\title{
Durability-Based Optimal Design Methodology for RC Members in Corrosive Environment
}

\author{
Saeid A. Alghamdi, Shamsad Ahmad, and Adamu Lawan \\ Department of Civil and Environmental Engineering, King Fahd University of Petroleum \& Minerals, \\ P.O. Box 1896, Dhahran 31261, Kingdom of Saudi Arabia
}

\begin{abstract}
As durability-based design of reinforced concrete $(\mathrm{RC})$ structures in corrosive environments is highly influenced by chloride-induced corrosion of reinforcing steel bars, this paper first presents brief outline of an experimental investigation recently carried out by the authors on a large number of reinforced concrete test specimens subjected to several scenarios of chloride-driven reinforcement corrosion. Concrete specimens were prepared with cementitious material content of 350,375 , and $400 \mathrm{~kg} / \mathrm{m}^{3}$; water-cementitious ratios of $0.4,0.45$, and 0.5 ; fine to total aggregate ratios of $0.35,0.4$, and 0.45 ; and cover thickness of $25,37.5$, and $50 \mathrm{~mm}$. The specimens were then exposed to chloride solution of three different concentrations and were tested for determining corrosionrate using electrochemical and gravimetric-weight loss methods. Numerical analysis of reinforcement-corrosion rates (determined electrochemically and gravimetrically) was first used to determine statistical correlation between corrosion rates obtained by the two methods. Then, the gravimetric reinforcement-corrosion rate results were utilized for developing regression models for reinforcement corrosion rates in terms of concrete quality parameters, concrete cover-thickness, and chloride concentration. The regression models obtained for reinforcement-corrosionrates were adapted within an automated analysis-design-methodology using Microsoft Excel solver for durabilitybased optimal design of RC members subjected to specified chloride exposure corrosive environments. Sample results obtained from the design methodology outlined in this paper are summarized for selected case studies of $\mathrm{RC}$ beams and columns.
\end{abstract}

\section{INTRODUCTION}

As regards the durability of reinforced concrete structures under known chloride-exposure conditions, chloride ions-driven corrosion of reinforcing steel is known to be a major design problem for RC structures. And while quality of concrete and cover thickness play a major role in initiation and progress of reinforcement corrosion, it is particularly noted that deterioration of RC structures in a corrosive environment (taking coastal region of SaudiArabia as an example) is mainly attributed to (i) extreme environmental conditions, (ii) substandard quality of construction materials, and/or (iii) inadequate construction practices. Environmental conditions of the area are characterized by wide variations in daily and seasonal temperatures (Saricimen, 1993). Such variations in day to night temperature lead to formation of microcracks in concrete matrix, which accelerates diffusion of aggressive species, such as chlorides, to surface of steel bars. The conditions required for initiating corrosion of reinforcing steel are satisfied, and the resulting corrosion products of confined steel bars would produce expansive forces of magnitude that may exceed by far the tensile strength of concrete matrix (Dyer, 2014). Therefore, reinforced concrete structures in such environments should be designed to satisfy both durability and strength requirement (Alghamdi \&
Ahmad, 2010; Shameem, Maslehuddin, Saricimen, \& Al-Mana, 1995).

For carrying out structural durability-based design of $\mathrm{RC}$ members, the following two effects of degradations in concrete and steel should therefore be considered:

(i) loss of concrete cover leading to reduced crosssectional area of the concrete due to surface deterioration; and

(ii) loss of steel cross-sectional area, steel-to concrete bond, and loss of concrete cover due to expansive forces resulting from reinforcement corrosion products.

For RC structures under aggressive-exposure conditions, excluding frost attack, a model for evaluating the rate of deterioration of surface concrete $C_{r}(\mathrm{~mm} /$ year; being the rate of loss of structurally effective concrete), a model was previously given (Pihlajavaara, 1994) as follows in Eq. 1:

$$
C_{r}=\frac{C_{e n v} C_{c u r}}{f_{c k}^{3.3}}
$$

where $C_{\text {env }}=$ environmental coefficient; $C_{\text {cur }}=$ curing coefficient; and $f_{c k}=$ characteristic cubic compressive strength of concrete at 28 days (MPa). 
In the Gulf region (within latitude $10^{\circ}-30^{\circ}$ ), values of $c_{\text {env }}$ were assumed to be within the range of $10-500 \times 10^{3}$ (Pihlajavaara, 1994), and the curing coefficient, $C_{\text {cur }}$, may be calculated by using the following equation (Vesikari, 1995).

$$
C_{\text {cur }}=\frac{1}{0.85+0.17 \log _{10}(d)}
$$

where $d$ = the curing time (days).

Loss rate of structurally effective concrete $C_{r}$, is calculated by using Eq. 1, and the reduced crosssectional area of concrete, at any exposure time $t$, may be calculated by using $C^{\prime}(t)$ from Eq. 3:

$$
C^{\prime}(t)=C_{r}(t)
$$

The cross-section residual dimensions [namely, width $b^{\prime}(t)$ and depth $h^{\prime}(t)$ ] for a concrete member at any exposure time $t$, may be calculated using Eqs. 4 and 5:

$$
\begin{aligned}
& b^{\prime}(t)=b_{o}-2 c^{\prime}(t) \\
& h^{\prime}(t)=h_{o}-2 c^{\prime}(t)
\end{aligned}
$$

where $b_{0}$ and $h_{0}$ are, respectively, initial width and depth of a given RC member.

Value of corrosion penetration rate $P_{r}$ is determined using Eq. 6,

$$
P_{r}=\frac{W}{F \gamma_{s t}} I_{c o r r}
$$

where $\gamma_{\text {st }}=7.85 \mathrm{~g} / \mathrm{cm}^{3} ; F=96500 \mathrm{~A} \cdot \mathrm{s} ; W=27.93 \mathrm{~g}$; The loss of steel-rebar diameter $d^{\prime}(t)$ leading to a reduced cross-sectional area of steel at any exposure time $t$ is calculated using Eq. 7 .

$$
d^{\prime}(t)=P_{r}(t)
$$

Then, a reduced diameter $D^{\prime}(t)$ of rebar at any exposure time $t$ is given by Eq. 8 ,

$$
D^{\prime}(t)=D_{0}-2 d^{\prime}(t)
$$

where $D_{\mathrm{o}}$ is the initial diameter of rebar.

The main objectives of this research work are to

(a) determine reinforcement corrosion rate using electrochemical and gravimetric techniques on a large number of concrete specimens designed with specified combinations of design variables including water-cementitious material ratio $(w / c)$, cementitious material content, fine to total aggregate ratio, and cover thickness;

(b) determine correlation between electrochemically and gravimetrically measured reinforcement corrosion rates; and

(c) outline and demonstrate utilization of a methodology for durability-based design of RC members in a specified corrosive environments.

\section{EXPERIMENTAL PROGRAM}

\subsection{Construction materials and properties}

This research study is based on type I Normal Portland Cement used with $8 \%$ Silica Fume added to all concrete mixtures. All concrete test specimens were prepared with aggregates obtained from two different sources located in the eastern and western regions of the Kingdom (namely, Abu Hadriyah quarries and Taif quarries), referred to hereafter as H-type and T-type aggregates, samples of which are shown in Figure 1. The T-type aggregate is composed mainly of coarse-grained silicate minerals (such as quartz and feldspar) known to produce weaker bonds with cement paste than the $\mathrm{H}$-type (mainly calcareous rocks, such as limestone and dolomite). And with the established influence of aggregates-type, based on mineralogical and petrographic characteristics (Bérubé, 2001), on durability of concrete matrix and RC structures in corrosive environments (Saricimen, 1993), the characteristics of the two types of coarse aggregates were previously studied (Alghamdi \& Ahmad, 2010). Development of microcracking at materials' interface lines and harmful levels of concrete permeability (consequentially undermining structural durability) are invariably caused by particular types of coarse aggregates. As such, coarse aggregates' properties were identified as most influential on thermal and stiffness characteristics and incompatibilities between concrete-matrix constituents. And for the purpose of this research work, specific gravity and water absorption of used coarse aggregates were determined, and abrasion test results were obtained (respectively, in accordance with ASTM C128 and ASTM C131), and the results are listed in Table 1. The specific gravity and absorption of fine aggregate were found to be 2.6 and $0.57 \%$, respectively. Super-plasticizer was added during mix design with low water-cement ratio, in order to enhance workability of concrete mixtures.

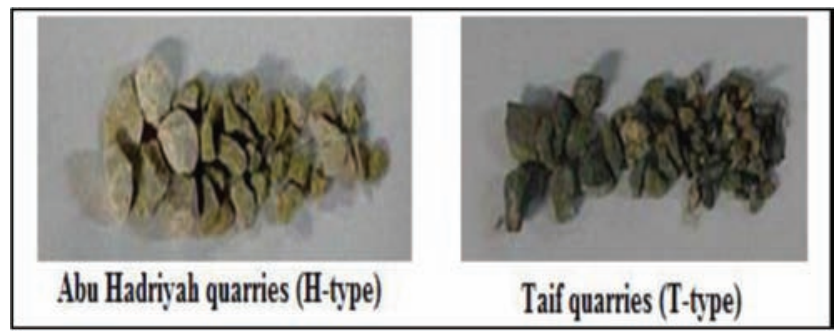

Figure 1. Samples of the two types of coarse aggregates used. 
Table 1. Coarse aggregates properties.

\begin{tabular}{lccc}
\hline Aggregate source & $\begin{array}{c}\text { Specific } \\
\text { gravity }\end{array}$ & $\begin{array}{c}\text { Water } \\
\text { absorption (\%) }\end{array}$ & $\begin{array}{c}\text { Abrasion } \\
\text { loss (\%) }\end{array}$ \\
\hline Abu Hadriyah $(\mathrm{H})$ & 2.55 & 1.10 & 28.86 \\
Taif $(\mathrm{T})$ & 2.88 & 2.01 & 37.84 \\
\hline
\end{tabular}

\subsection{Test specimens and concrete mix design}

Steel bars of diameter $16 \mathrm{~mm}$ were centrally placed in each one of 486 cylindrical concrete test specimens with height of $150 \mathrm{~mm}$; diameters of 66, 91, and $116 \mathrm{~mm}$; and with three different cover thicknesses of $25,37.5$, and $50 \mathrm{~mm}$. Test specimens were prepared to evaluate corrosion rate and epoxy coating was applied to steel bar at bottom-end and at interfaceend extending from within top-end of concrete-matrix upwards as shown in Figure 2.

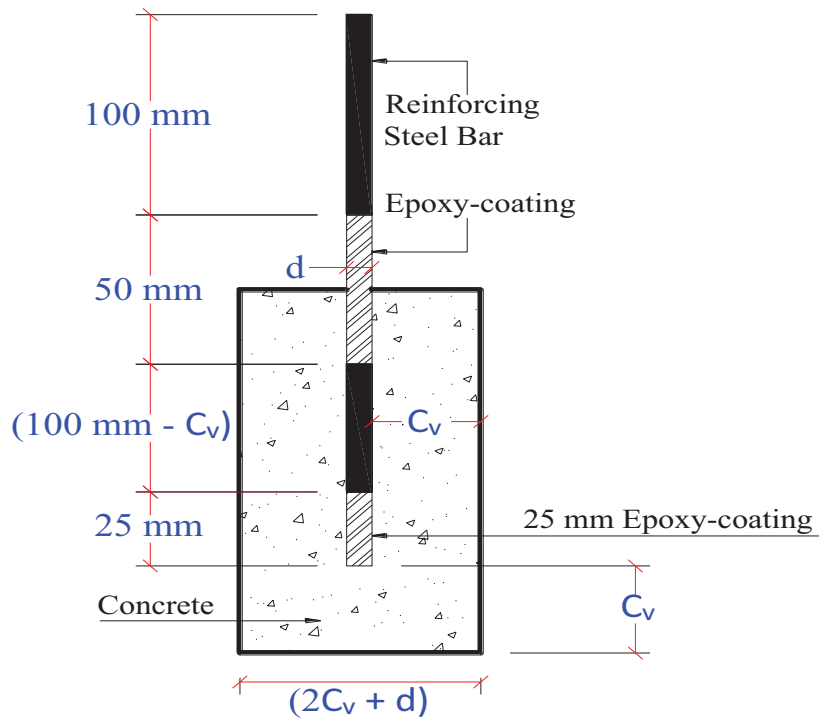

Figure 2. Details of typical test specimen.

Absolute volume method was employed for the concrete mix design. The groups of water-cementitious ratio, cementitious material content, and fine to total aggregate ratio used to prepare the specimens were respectively $\left(R_{\mathrm{w} / \mathrm{c}}: 0.4,0.45\right.$, and 0.5$),\left(C_{\mathrm{c}}: 350,375\right.$, and $\left.400 \mathrm{~kg} / \mathrm{m}^{3}\right)$, and $\left(R_{\mathrm{F} / \mathrm{T}}: 0.35,0.4\right.$, and 0.45$)$. Three chloride concentrations of 3,7 , and $12 \%$ were used to simulate corrosive conditions. And in order to obtain homogenous concrete matrix having uniform consistency without segregation, all constituents were uniformly mixed together, with the addition of potable water and super-plasticizer, using a revolving drumtype mixer.

Test specimens were de-molded after $24 \mathrm{~h}$ of concrete casting, and specimens were then cured for a period of 28 days in water tanks under laboratory conditions and were subsequently partly submerged in chloride solutions to allow corrosion to take place. Samples of test specimens exposed to a chloride solution are shown in Figure 3.

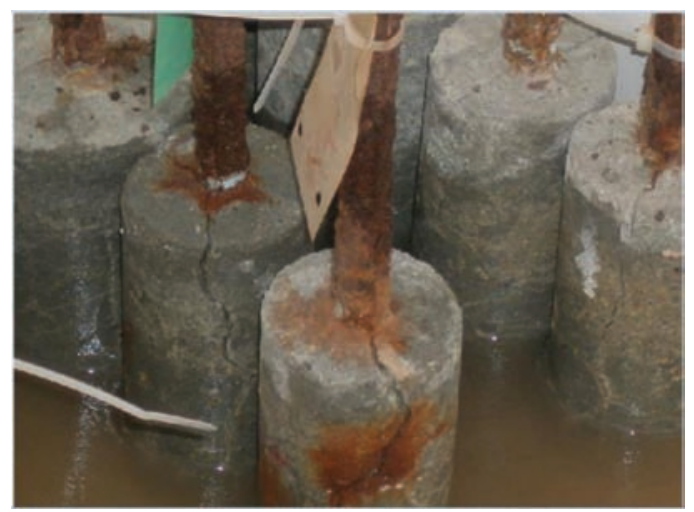

Figure 3. Sample of test-specimens exposed to chloride solution.

\subsection{Experimental program}

\subsubsection{Linear polarization resistance method (LPRM)}

The LPRM was employed to measure the corrosion current density $\left(I_{\text {corr }}\right)$ using PARSTAT 2273 potentiostat equipment (PowerCORR, 2001). As a means of evaluating the instantaneous corrosion rate of reinforcing steel in concrete, the technique is applied to measure corrosion current density using a threeelectrode system comprising: (i) reference electrode; (ii) counter electrode (steel plate) which was connected to the respective terminals of the potentiostat; and (iii) steel reinforcement in the concrete specimen (often known as the working electrode) polarized to $\pm 20 \mathrm{mV}$ from its equilibrium (rest) potential at a perturbation scan rate of $0.166 \mathrm{mV} / \mathrm{s}$.

Steel reinforcement was then polarized after an appropriate initial delay of about $1 \mathrm{~min}$, and the linear polarization resistance $R_{p}\left(\mathrm{k} \Omega \cdot \mathrm{cm}^{2}\right)$ was determined from the slope of the applied potential versus measured current plot. Corrosion current density $I_{\text {corr }}\left(\mu \mathrm{A} / \mathrm{cm}^{2}\right)$ is then calculated using Eq. 9.

$$
I_{\text {corr }}=\frac{B}{R_{p}}
$$

where $B=\frac{\beta_{a} \beta_{c}}{\left(\beta_{a}+\beta_{c}\right)}$ (with $\beta_{a}$ and $\beta_{c}$ being, respectively, anodic and cathodic Tafel constants); $R_{p}=$ polarization resistance $\left(\mathrm{k} \Omega \cdot \mathrm{cm}^{2}\right)$.

A Tafel plot is normally utilized to find Tafel constants, but when the plot is not available, $B$-values of 26 and $52 \mathrm{mV}$ have been recommended (Al-Tayyib \& Khan, 1988) for steel bars in active and passive 
states, respectively. In this work, a value of $26 \mathrm{mV}$ was used.

\subsubsection{Gravimetric weight loss method (GWLM)}

Following corrosion rate measurements using LPRM, all concrete samples were then broken for determination of corrosion rate by gravimetric weight loss method. Preparation, cleaning, and estimation of weight loss were done in accordance with ASTM G103 . The cleaning solution was prepared by adding $20 \mathrm{~g}$ of antimony trioxide and $50 \mathrm{~g}$ of stannous chloride in $1000 \mathrm{ml}$ of hydrochloric acid. Samples of corroded steel bars obtained from test specimens before and after cleaning are shown in Figure 4.

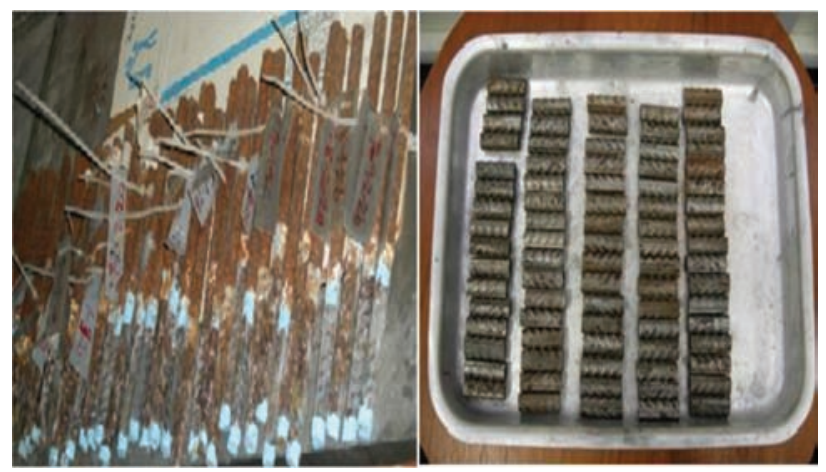

Figure 4. Samples of corroded rebars before and after cleaning.

The weight loss $\Delta W$ was calculated as

$$
\Delta W=W_{i}-W_{f}
$$

where $W_{i}=$ initial weight of the bars before corrosion (g) and $W_{f}=$ weight of the bars after cleaning all rust products $(\mathrm{g})$.

Then the corrosion penetration rate, $P_{r}$ ( $\mu \mathrm{m} /$ year) was determined using Eq. 11:

$$
P_{r}=\frac{1.116 \times 10^{7} \times \Delta W}{A \times T}
$$

in which $A=$ exposed surface area of rebar $\left(\mathrm{cm}^{2}\right)$ and $T=$ exposure time (hours).

Corrosion penetration rate $P_{r}$ was converted to corrosion current density $l_{\text {corr }}$ using a simplified relationship (Alghamdi \& Ahmad, 2010) given by Eq. 12:

$$
I_{\text {corr }}=\frac{P_{r}}{11.7}
$$

\section{RESULTS AND DISCUSSION}

\subsection{Correlation between $I_{\text {corr,g }}$ and $I_{\text {corr,e }}$}

Values of reinforcement corrosion rate measured in terms of corrosion current density using electrochemical and gravimetric methods (designated as $I_{\text {corr,e }}$ and $I_{\text {corr,g, }}$, respectively) obtained for all the test specimens were analyzed with full details presented previously (Alghamdi \& Ahmad, 2010). A close inspection of results obtained indicates that effects of aggregate type, cover thickness, and chloride concentration on correlation between the corrosion current density determined by LPRM and GWLM are practically insignificant. Hence, a single plot of corrosion current density values determined by LPRM against corresponding corrosion current density values determined by GWLM for all 486 test specimens is shown in Figure 5 in which good correlation between $I_{\text {corr, }}$ and $I_{\text {corr.e }}$ values are clearly reflected by correlation coefficient value nearly equal to 0.96 . Correlation analysis also indicates that value of gravimetric corrosion current density is, on average, nearly equal to $86 \%$ of values of electrochemical corrosion current density.

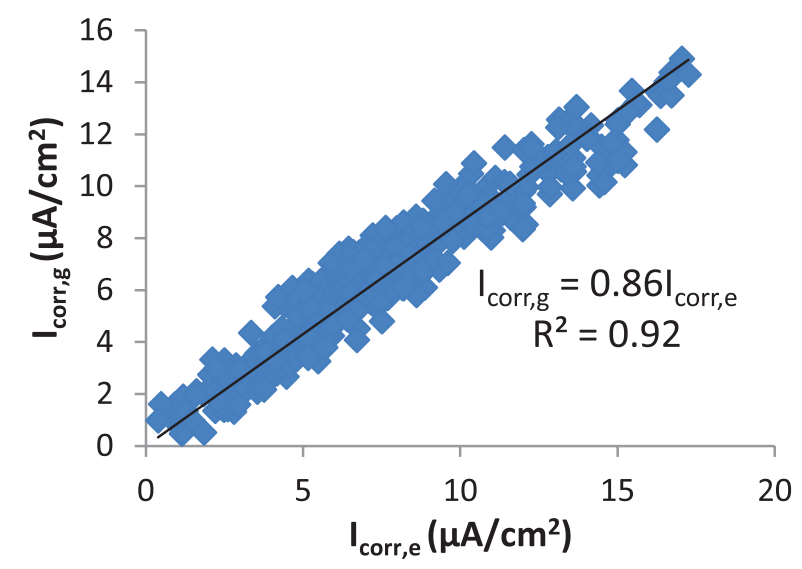

Figure 5. Correlation of $I_{\text {corr,g }}$ to $I_{\text {corr,e }}$ for all test specimens.

\subsection{Regression models for corrosion rate}

Since gravimetrically computed reinforcement corrosion rates were found to be more accurate and reliable, the models for predicting corrosion current density in terms of water-cementitious materials ratio (w/cm ratio), fine to total aggregate ratio, cover thickness, cementitious materials content, and chloride concentration were developed using Minitab software (Alghamdi \& Ahmad, 2010), separately for the two aggregate types using gravimetric data. A linear-type regression model was selected considering the linear variation of corrosion rate with major design factors (including $R_{w / c}, C_{c}, R_{F / T}$, $C_{L}$, and $C_{v}$ ) affecting corrosion rate. Regression models for corrosion current density obtained for both types of aggregates are presented in Table 2. 
Table 2. Regression models for corrosion current density.

\begin{tabular}{|c|c|c|}
\hline Aggregate type & Regression models & $\mathbf{R}^{2}$ \\
\hline $\mathrm{H}$ & $\begin{aligned} l_{\text {corr }}= & -13+34.4 R_{w / c}+0.024 C_{c} \\
& +3.83 R_{F / T}+0.097 C_{L}-0.181 C_{v}\end{aligned}$ & 0.82 \\
\hline $\mathrm{T}$ & $\begin{aligned} I_{\text {corr }}= & -18.4+43.8 R_{w / c}+0.03 C_{c} \\
& +4.77 R_{F / T}+0.12 C_{L}-0.203 C_{v}\end{aligned}$ & 0.94 \\
\hline
\end{tabular}

\subsection{Durability-based optimal design methodology}

Durability-based design of typical RC members can be performed by utilizing regression models (outlined in the previous section) for prediction of corrosion current density. For a specified design service life (Sarja \& Vesikari, 1996), the minimum value of corrosion current density $I_{\text {corr }}$ were used to determine loss of steel rebar due to corrosion and was then utilized within a durability-based optimal structural design search methodology.

The following five-step design procedure (Alghamdi \& Ahmad, 2010) was utilized for durability-based design $\mathrm{RC}$ beams and columns:

(i) Microsoft Excel solver is used to determine optimum values of water to cementitious material ratio $\left(R_{w / C}\right)$, cementitious material content $\left(C_{C}\right)$, concrete cover $\left(C_{V}\right)$, and fine to total aggregate ratio $\left(R_{F / T}\right)$ corresponding to minimum corrosion current density $I_{\text {corr,g }}$ for specified chloride concentration using the models developed for $I_{\text {corr,g }}$.

(ii) Compressive strength ${f^{\prime}}_{c}$ and elastic modulus $E_{c}$ of concrete are determined using optimum values of $R_{W / C}, C_{C}$, and $R_{F / T}$ in the following models (Adamu, 2011).

$$
\begin{aligned}
f_{c}^{\prime}= & -61.24-0.056 C_{c}-19.87 \\
& \operatorname{Exp}\left(2.083 R_{w / c}\right)+183.45 R_{F / T}^{0.119} \\
E_{c}= & -49.10-0.0048 C_{c}-13.23 \\
& \operatorname{Exp}\left(2.083 R_{w / c}\right)+145.68 R_{F / T}^{0.106}
\end{aligned}
$$

(iii) Loss rates of concrete cover and rebar diameter are determined from Eqs. 3 and 7 using the data obtained in steps (i) and (ii) given above. A preliminary section is then specified for a given structural member and the residual dimensions of cross-section and rebar diameter are determined.

(iv) A durability-based structural design of RC concrete members is performed using design information obtained in step (iii) given above.

(v) Adequacy of final cross-section and rebar diameter is checked against prescribed design requirements.
The design methodology for carrying out durabilitybased optimal structural designs is outlined in the flowcharts shown in Figures 6 and 7 for design of $\mathrm{RC}$ beams and columns, respectively. The design procedure was implemented in two Microsoft Excel programs (designated as: RC_B_DDesign and RC_C_DDesign) suitable for automated design of $\mathrm{RC}$ beams and columns, respectively, in corrosive environment. Sample values of typical input and output results obtained for durability-based design of typical design case studies for RC beams and columns are summarized in Tables 3 and 4 , respectively.

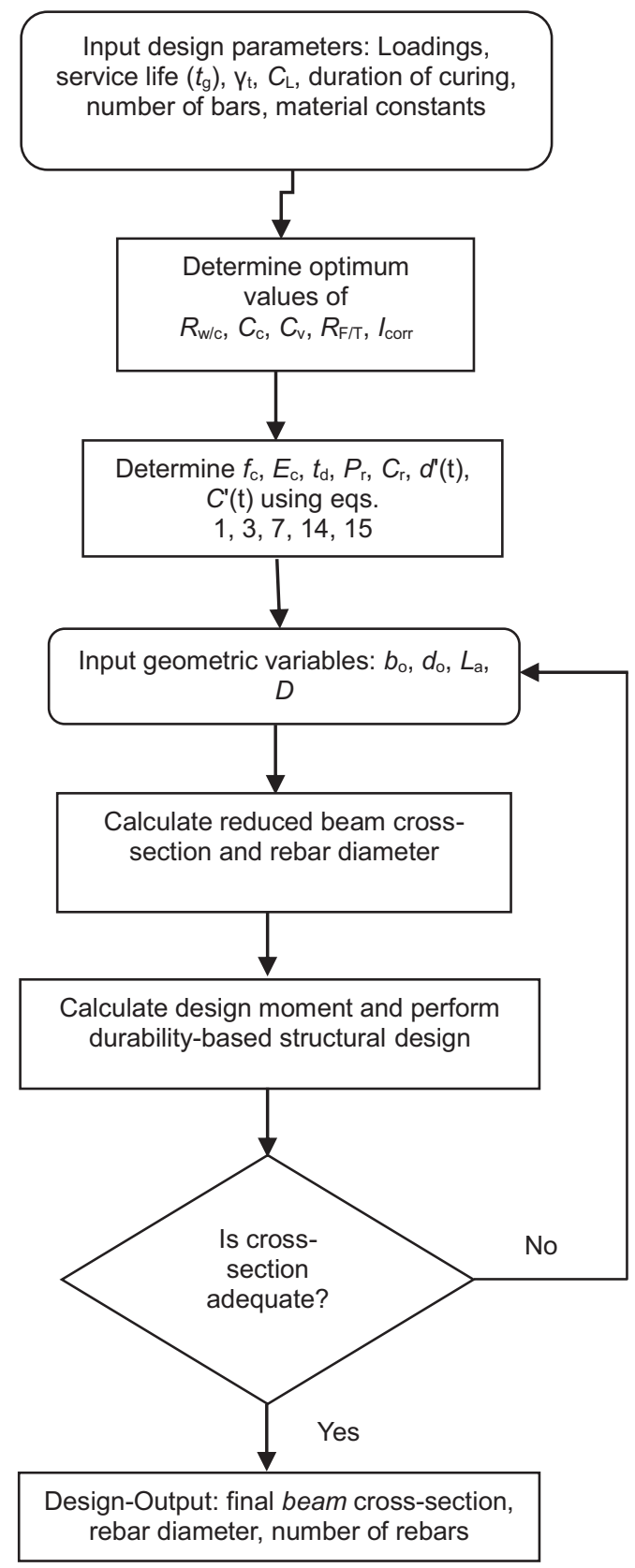

Figure 6. Flowchart for durability-based design of RC beam. 
Input design- parameters: Loadings, service life $\left(t_{\mathrm{g}}\right), \gamma_{\mathrm{t}}, C_{\mathrm{L}}$, Duration of curing, number of bars, material constants

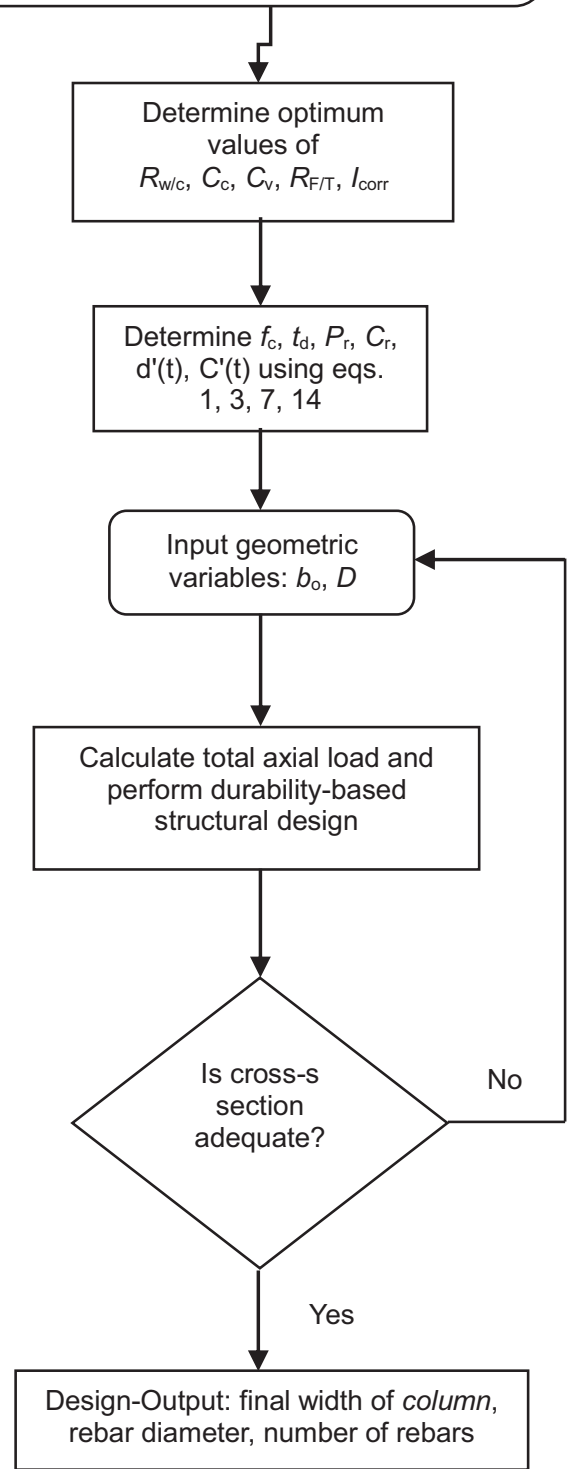

Figure 7. Flowchart for durability-based design of RC column.

\section{CONCLUSION}

In this research study, 486 concrete specimens with centrally placed reinforcing steel bar were subjected to experimental conditions for chloride-induced corrosion. The study was conducted to develop correlation relationship between corrosion current density values determined based on data compiled from linear polarization resistance method (LPRM) and gravimetric weight loss method (GWLM). Reliable models for prediction of reinforcement corrosion rate were also developed and utilized within an automated methodology for durability-based design of RC beams and columns. And to demonstrate utilization of the
Table 3. Sample design results obtained by RC B_DDesign program for durability-based optimal design of $\mathrm{RC}$ beam. ${ }^{*}$

\begin{tabular}{|c|c|c|c|c|c|}
\hline \multirow[b]{2}{*}{$\mathbf{S} / \mathbf{N}$} & \multicolumn{2}{|c|}{$\begin{array}{l}\text { Input design } \\
\text { values }\end{array}$} & \multicolumn{3}{|c|}{ Optimal design values } \\
\hline & $\begin{array}{l}\text { Target } \\
\text { life, } t_{g} \\
\text { (years) }\end{array}$ & $\begin{array}{l}\mathrm{C}_{\mathrm{L}} \\
(\%)\end{array}$ & $\begin{array}{c}\text { Beam- } \\
\text { width } \\
b_{\text {optim }}(\mathrm{mm})\end{array}$ & $\begin{array}{c}\text { Beam- } \\
\text { depth, } \\
d_{\text {optim }}(\mathrm{mm})\end{array}$ & $\begin{array}{c}\text { Bar diameter } \\
\mathrm{D}_{\text {optim }}=\mathrm{D}+\Delta \mathrm{D} \\
(\mathrm{mm})\end{array}$ \\
\hline 1 & & 3 & 200 & 528 & 18.11 \\
\hline 2 & 40 & 7 & 200 & 403 & 20.71 \\
\hline 3 & & 12 & 200 & 310 & 23.59 \\
\hline 4 & & 3 & 225 & 436 & 19.60 \\
\hline 5 & 50 & 7 & 225 & 331 & 22.49 \\
\hline 6 & & 12 & 225 & 300 & 23.63 \\
\hline 7 & & 3 & 225 & 345 & 22.04 \\
\hline 8 & 70 & 7 & 225 & 300 & 23.63 \\
\hline 9 & & 12 & 225 & 300 & 23.63 \\
\hline
\end{tabular}

*Note: Length $=3 \mathrm{~m}$; dead-load $=40 \mathrm{kN} / \mathrm{m}$; live-load $12 \mathrm{kN} / \mathrm{m}$; $\Delta \mathrm{D}=$ additional increment to steel bar diameter to off-set corrosion effect.

Table 4. Sample design results obtained by RC_C_DDesign for durability-based optimal design of RC column.

\begin{tabular}{ccccc}
\hline & \multicolumn{2}{c}{ Input design values } & \multicolumn{2}{c}{ Optimal design values } \\
\cline { 2 - 5 } S/N & $\begin{array}{c}\text { Target service } \\
\text { life, } t_{\mathrm{g}} \text { (years) }\end{array}$ & $\begin{array}{c}\boldsymbol{C}_{\mathrm{L}} \\
(\mathbf{\%})\end{array}$ & $\begin{array}{c}\text { Column } \\
\text { width, } \boldsymbol{b}_{\text {optim }} \\
(\mathbf{m m})\end{array}$ & $\begin{array}{c}\text { Bar diameter, } \\
\boldsymbol{D}_{\text {optim }}=\boldsymbol{D}+\mathbf{D} \\
(\mathbf{m m})\end{array}$ \\
\hline 1 & \multirow{3}{*}{40} & 3 & 150 & 15.76 \\
2 & & 7 & 150 & 15.76 \\
3 & & 12 & 150 & 15.76 \\
\hline 4 & & 3 & 150 & 15.76 \\
5 & 50 & 7 & 150 & 15.76 \\
6 & & 12 & 170 & 15.76 \\
\hline 7 & & 3 & 150 & 15.76 \\
8 & 70 & 7 & 268 & 15.76 \\
9 & & 12 & 650 & 15.76 \\
\hline
\end{tabular}

*Note: Dead-load $=100$ kN; live-load $=120$ kN.

design methodology, the results obtained from design case studies of sample RC beams and columns are summarized and presented in this paper.

\section{ACKNOWLEDGMENTS}

This research work was conducted and completed under research grant (ID KACST AT-23-21) provided by the King Abdulaziz City for Science \& Technology (KACST; Riyadh-KSA). The authors acknowledge with appreciation, the financial and logistical supports provided by both KACST and the Department of Civil and Environmental Engineering at King Fahd University of Petroleum and Minerals (KFUPMDhahran). 


\section{REFERENCES}

Adamu, L. (2011). Electrochemical and gravimetric studies towards service-life prediction and durability-based design of RC structures in corrosive environments (M.Sc. thesis submitted to the Deanship of Graduate Studies). King Fahd University of Petroleum and Minerals, Dhahran, Saudi Arabia.

Ahmad, S., \& Alghamdi, S. A. (2014). A statistical approach to optimizing concrete mixture design. The Scientific World Journal, 7. Article ID 561539.

Al-Tayyib, A. J., \& Khan, M. S. (1988). Corrosion rate measurement of reinforcing steel in concrete by electrochemical techniques. ACI Materials Journal, 171-177.

Alghamdi, S. A., \& Ahmad, S. (2010). Multi-criterion optimal designs of $R C$ beams and columns: experimental and analytical studies. (Final Report, Research Project AT-23-21).

ASTM C 128-07a. Standard test method for density, relative density (specific gravity) and absorption of fine aggregate. West Conshohocken, PA: Author.

ASTM C 131. (2006). Standard test method for resistance to degradation of small-size coarse aggregate by abrasion and impact in the Los Angeles machine. West Conshohocken, PA: Author.

ASTM G 1-03. (2003). Standard practice for preparing, cleaning, and evaluating corrosion test specimens. West Conshohocken, PA: Author.

Bérubé, M.-A. (2001). The mineralogical and petrographic analysis of concrete aggregates.
Journal of Mineralogy Overview (JMO), 53(12), 45-47.

Dyer, T. (2014). Concrete durability. Boca Raton, FL: CC Press, Taylor \& Francis Group.

MINITAB. (2000). Statistical package. Release 13 for Windows 95 and 98.

Pihlajavaara, S. E. (1994). Contributions for the development of the estimation of long-term performance and service-life of concrete. (Report 3, Articles 49). Espoo, Finland: Helsinki University of Technology, Faculty of Civil Engineering and Surveying, pp. 1-26.

PowerCORR. (2001). User's manual, corrosion measurement software. USA: Princeton Applied Research.

Saricimen, H. (1993). Concrete durability problems in the Arabian Gulf region - a review. Proceedings, Fourth International Conference Deterioration and Repair of R.C. in the Arabian Gulf, Bahrain.

Sarja, A., \& Vesikari, E. (1996). Durability Design of Concrete Structures. Report of RILEM Technical Committee, E \& FN Spon.

Shameem, M., Maslehuddin, M., Saricimen, H., \& Al-Mana, A. I. (1995). Extending the life of reinforced concrete structures in the Arabian Gulf environment. Proceedings, Structural Faults and Repairs Conference, London, England, 115-126.

Vesikari, E. (1995). Service-life design of concrete structures. RIL 183-4.9, Association of Finnish Civil Engineers, RIL: Helsinki, Finland. 